\title{
ENVIRONMENT DESIGN FOR HUMAN-ROBOT SYMBIOSIS - INTRODUCTION OF WABOT-HOUSE PROJECT -
}

\author{
Shigeki SUGANO \\ Department of Mechanical \\ Engineering, \\ Waseda University \\ 3-4-1 Ookubo Shinjuku Tokyo \\ 169-8555, Japan \\ sugano@waseda.jp
}

\author{
Yuko SHIRAI \\ WABOT-HOUSE Laboratory, \\ Waseda University \\ 3-4-1 Ookubo Shinjuku Tokyo \\ 169-8555, Japan \\ sri@waseda.jp
}

\author{
Soungho CHAE \\ Advanced Research Institute for \\ Science and Engineering, \\ Waseda University \\ 3-4-1 Ookubo Shinjuku Tokyo \\ 169-8555, Japan \\ chae@waseda.jp
}

\begin{abstract}
In this article, we would like to introduce the WABOT-HOUSE project. The attraction of the Waseda University, the School of Science and Engineering, through the Gifu prefecture was the cue of the project. In consequence, the WABOT-HOUSE is the co-operation project with industrial and administrative sectors. Its goal is to encourage the regional industry and to develop region itself due to the new technology robotics in the Gifu prefecture. In order to prepare the lifestyle with robots and to launch the robotic industry, we need to create a demonstrative space and social system for human-robots symbiosis. Kagamigahara-City, where WABOT-HOUSE laboratory locates, has been already designated for the special zone for robotics by the Japanese government. We are also ready for conducting the pilot programs for robots. Therefore we research and develop not only robotics itself but also planning theories of space, construction methods and social systems for the human-robot symbiosis.
\end{abstract}

Keywords: Symbiosis, Robot, House, Social System

\section{INTRODUTION}

1.1 Background

A wide range of new technologies relating to robots has recorded a dynamic development above all in the entertainment field. However, the robot technology relating to human-robot symbiosis has rather been underestimated. The advanced adaptability of robots to humanity and environment is highly required in the aging society and in the symbiotic future with natural environment. That is because existing robotic researches have focused mainly on the more advanced function of the robots themselves. Therefore, they didn't care much about the environment where the robots were to live. Thus researches on a space where men could share their life with robots in comfort should be done. It goes without saying that the social systems should support the practical use of the new technology robotics in the future. Accordingly, the WABOT-HOUSE is our way of solving these issues. We research and develop not only robotics itself but also planning theories of space, construction methods and social systems for the human-robot symbiosis.

1.2 Foundation of WABOT-HOUSE

To begin with artificial legs and hands, Waseda University has a long history as one of the leading institute for anthropomorphic robots. It extends more than 30 years since 1970. We have had the first great success in developing WABOT-1, which is the world first biped walking humanoid robot in 1973, WABOT-2 in 1984 and Hadaly and WABIAN in 1997, Waseda Humanoid Robot Project has been studying the human-robot symbiosis. As well, we have made significant technological advancements in the architectural field where we have introduced numerous novel designs and proposed new building methods.
The Gifu Prefecture has on the other hand constructed an R\&D site named Techno Plaza in Kakamigahara since 1998. Gifu has aimed at sophisticating and introducing IT technologies for the local industry and, farther more, creating a new industry. Kakamigahara and her suburb is also a metal-processing industrial region. This technological accumulation leads to an expectation that the robotics industry can suit as a next economical impact for the region. That is why the Gifu prefecture has attracted the School of Science and Engineering at the Waseda University in Kakamigahara. A research block of the WABOT-HOUSE Laboratory was soon begun to construct in the Techno Plaza. Many researchers station there on a full-time basis, and work for a better communication among local enterprises, residents of the prefecture.

By the way "WABOT" is the abbreviation of "Waseda Robot". And then the name "WABOT-HOUSE" was given by the time of its establishment in 2001 .

\subsection{Feature of WABOT-HOUSE}

Several projects have been made on the technologies of structured environment for robots. However such a project in tight co-operation with the local government as this is the first experiment of its kind. The end-users are also the members of our project. Moreover we try to devise some social system from the newly technological point of view. It is a very novel way of thinking, because some technologies have been developed to overcome the restrictions from the social systems at present such as hybrid electric and fuel cell vehicles (HEV). For that reason our approach represents a 180-degree turn in the $\mathrm{R} \& \mathrm{D}$ to perform our role in the society. And then Kagamigahara-City and Gifu-City in the Gifu prefecture have been already designated for the special zone for robotics by the Japanese government. Therefore the 
Kagamigahara-City, where WABOT-HOUSE laboratory locates, is ready for conducting the pilot programs for robots. We are expected to consider an innovative spatial and social system with robotics as a new technology.

In this article, we would like to introduce the WABOT-HOUSE project. At first, the aim of the project is to mention. The third chapter will describe the robots developed in this project. In the fourth chapter the architectural aspect will be presented. The last chapter mentions the co-operation with industrial and administrative sectors.

\section{AIMS OF WABOT-HOUSE PROJECT}

The aims of WABOT-HOUSE project are as follows:

(1) To develop the robotics in symbiosis with humans and nature

(2) To build the houses where humans and robots can live close together

(3) To devise the social systems which realize the practical use of robots for the future life and the symbiosis among robots, humans and their environment

Through these aims accomplished, we are expecting to stimulate regional industry in the Gifu prefecture and to encourage the region itself. For the purpose, WABOT-HOUSE, a research institute aiming for the making of technical theories and social systems, was opened as industrial, administrative and academic sectors cooperation project in Gifu prefecture. This project mobilizes not only researchers from robotics and mechanical engineering fields, but also researchers specialized in architecture, information and communication, art, educational sciences. Moreover we offer a platform of the cooperation among industrial, administrative, and academic sectors. Sharing ideas is a characteristic of this project.

\section{ROBOTS OF WABOT-HOUSE PROJECT}

We have developed a number of robots. Here we take up the robots related to the project, especially to the buildings of WABOT-HOUSE project. Followings are some examples of robots which we are developing and demonstrating with experiments in the WABOT-HOUSE buildings. Our basic statement "living together with people" means for robots "living in the human accommodation and the nature". As the result we also research the relationship between the architecture and robots as well as between the nature and robots. These robots below will be active in and out of the buildings of WABOT-HOUSE project in the $4^{\text {th }}$ chapter. We have four groups regarding robots as following.

1) Robot house

Developing a human-assisting humanoid robot, an emotional communication robot and more the technologies of structured environment for robots, the robot-house group is researching on the advance technology for human-robot symbiosis. For human-robot symbiosis we study not only on physical function of robots such as safety control, human-robot contact identification based on tactile recognition, but also on their mind acquisition such as intelligence, emotion and will. Especially these researches are collaborated with those of the first floor of the building B1 (Space for the demonstrative experiments).

(1)Robot realizing natural and emotional communication with humans (WAMOEBA-3), Sugano Lab.

(2)Human Symbiotic Robot (WENDY), Sugano Lab.

(3)Robot enjoying communicating by talk with humans (ROBISUKE), Kobayashi Lab.

(4)Moving Module, WABOT-HOUSE Lab. in Gifu Please refer to the following website for the Sugano laboratory and the Kobayashi laboratory.

URL: http://www.sugano.mech.waseda.ac.jp/ and http://www.pcl.cs.waseda.ac.jp/

2) Humanoid family

This group has researched and developed humanoids in symbiosis with humans. At the same time, they try to understand human being from engineering point of view, and study on the integrated mind-body mechanism of human being. The last WABIAN-2 was demonstrated in the 2005 World Exposition, Aichi, Japan. The robot has realized a more human-like walking pattern, with knees stretched through a waist motion. That was impossible for conventional bipedal walking robots which should walk with knees bent constantly. This was the very first in the world.

(1)Biped Humanoid Robot (WABIAN2), Takanishi Lab.

(2)Anthropomorphic Flutist Robot (WF-4RII),

Takanishi Lab.

(3)Emotion Expression Humanoid Robot (WE-4RII),

Takanishi Lab.

(4)Clinical Jaw Movement Training Robot (WY-5RVI),

Takanishi Lab.

Please refer to the following website for the Takanishi laboratory. URL: http://www.takanishi.mech.waseda.ac.jp/

3) Ecological Robot

The group develops a technology in symbiosis with natural environment. Some robots are to develop for an autonomous movement and self-support of energy in order to survive in the natural environment. The Gifu prefecture is known as "Land of timber and land of forest", because of its rich nature. Therefore these robots are expected to work together with humans in the natural environment of Gifu. In particular these researches in this group are collaborated with those of the building C. The last WOODY-1 was also demonstrated in the 2005 World Exposition, Aichi, Japan. Aiming at the practical use, Woody- 1 is at the moment under improvement through a consultation among different sectors.

(1)Robot walking outside autonomously using GPS (GPSY), Hashimoto Lab.

(2)Module Robot, Hashimoto Lab.

(3)Autonomous robot with three robot arms (Jirorex), Hashimoto Lab.

(4)Survival Robot in Outdoor Environment (Survivalino), Hashimoto Lab.

(5)A remote-controlled robot, Hashimoto Lab.

(6)Mowing robot, Hashimoto Lab.

(7)Robot assisting forestry work (WOODY-1), 
WABOT-HOUSE Lab. in Gifu

Please refer to the following website for the Hashimoto laboratory. URL: http://www.phys.waseda.ac.jp/shalab/

4) Medical robotics

This group aims at keeping up and improving the quality life for elderly people through engineering approach. We develop the surgical robots for minimally invasive surgery and rehabilitation gait-assisting robots for the aged people not going to be bedridden.

(1)Hydraulic driven flexible manipulator, Fujie Lab.

(2)Microscopic manipulator, Fujie Lab.

(3)Paracenteses robot, Fujie Lab.

(4)Multi-DOF brain retract manipulator, Fujie Lab. Please refer to the following website for the Fujie Lab.

URL: http://www.fujie.mech.waseda.ac.jp

\section{BUILDINGS OF WABOT-HOUSE PROJECT}

We have come to mention the architectural aspects. The construction of WABOT-HOUSE laboratory moves right along at the site in Techno Plaza in Gifu. We have already completed almost all the buildings. What will happen, when robots begin to live together closely with us in daily life? From such a point of view, we set our first purpose to consider a planning theory about space and system in symbiosis with robots. The design concepts of four buildings are shown in table 4.1.

\section{Table 4.1 Design Concept of Four Buildings}

$\begin{array}{ll}\text { Building A: } & \text { Space for humans } \\ \text { Buildings B: } & \text { Space for symbiosis between humans and robots } \\ & \text { B1: Space for the demonstrative experiments } \\ & \text { B2: Space for the researchers' station } \\ \text { Building C: } & \text { Space for robots }\end{array}$

These three buildings themselves in different types are also a result of our studies. We have considered developing a planning method or an effective management regarding with robotics and IT perspectives, a construction and production system through virtual-reality technology.

Besides we have aimed the healthy and comfortable life with using renewable energies. These buildings should realize a high ideal in environmental assessment, and the more through robotic controls. Figure 4.1 shows the picture of four buildings at present and figure 4.2 gives the site plan.

4.1 Building A: Space for humans

The building A works also as a cockpit, monitoring environmental information, controlling and managing the whole buildings. Further this building is planned on the basis of recycle-oriented ideas. We used only recycled materials in environmental circle of the region by construction. We are trying to combine the simulation in mind and the experimental life in real in order to appeal a new accommodation system to the society.

Please refer to the following website for the Ojima laboratory. URL: http://www.ojima.arch.waseda.ac.jp/

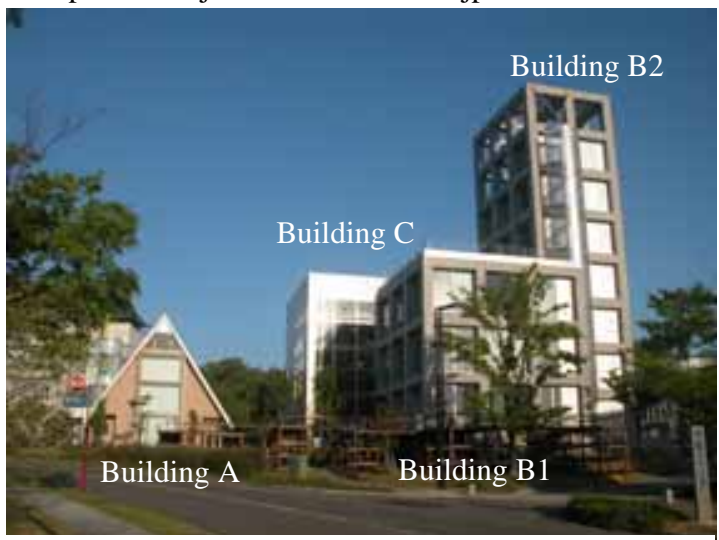

Fig.4.1 Picture of Four Buildings at Present

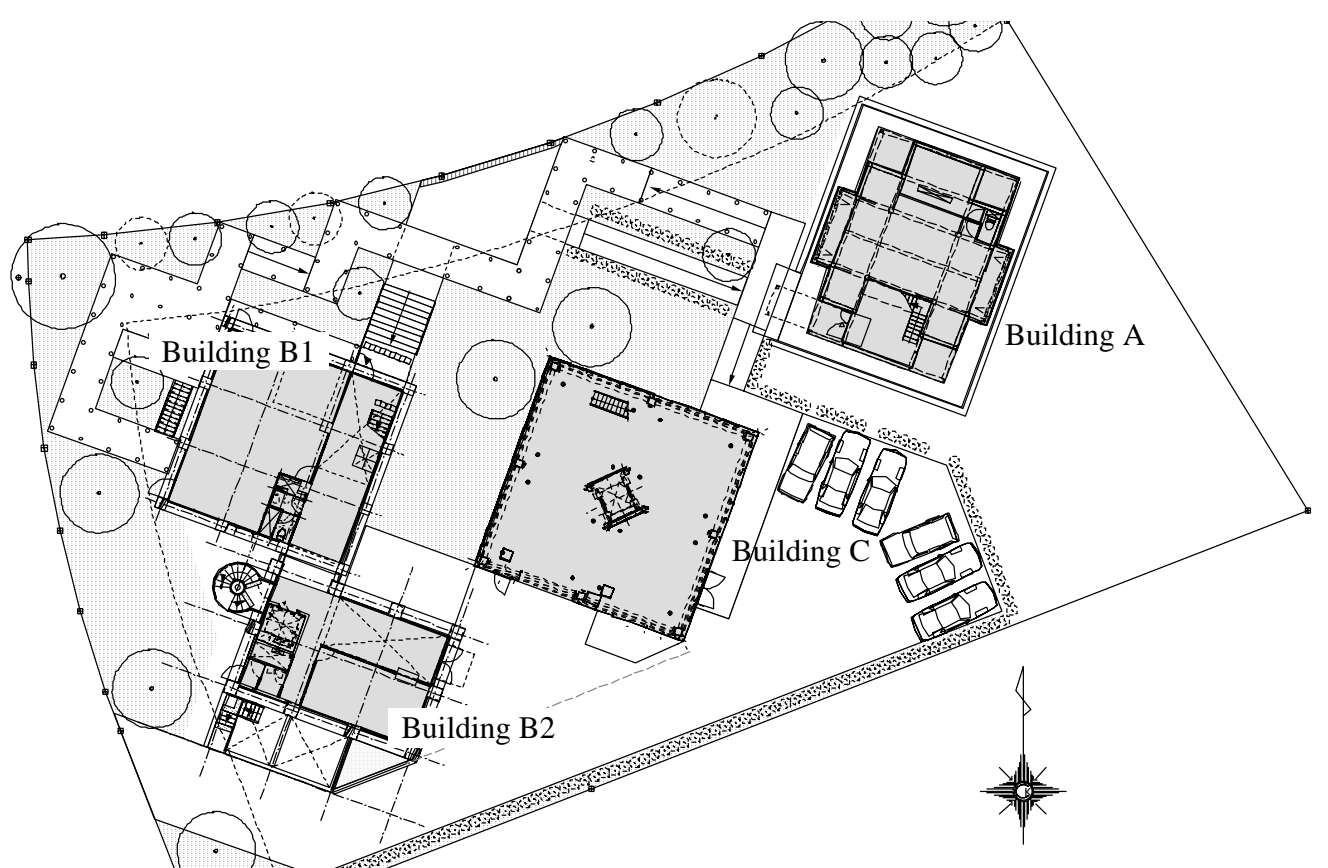

Fig.4.2 Site Plan 
4.2 Buildings B: Space for symbiosis between humans and robots

The first building $\mathrm{B}$ is the laboratory for the demonstrative experiments. That first floor is named "robot-house" laboratory. The second floor is the laboratory for robotics of medical treatment and welfare. And the last third floor is called "mechanics and electronics gaea". A section of this building is given in figure 4.3. And the second building $B$ is the researchers' station.

4.2.1 The first floor: "Robot-house" laboratory

The first floor of the first building B tries to serve above all as a research space on robots living with human beings at home. In the dining room/kitchen and the washroom, we are trying to find a good interaction between humankind and robots. Let us now show you some built-in technologies.

(1) Technologies of Structured Environment for Robots

When a robot lives in an existing human accommodation, it should recognize its own position and the circumstances. It means that we have to program the acting plan case by case. We have come to see how difficult it is to realize. Hence, we have changed our standpoint and took up "technologies of structured environment for robots”. We built the first floor of the B1 building under this concept und are researching the interaction between the robots and its environment.

(2) Positioning System

A system is now under development which supports to orient itself seamlessly in and out of the building. The system is supported by the global positioning system, GPS, outdoors and the pseudolite indoors. We use the pseudolite and the radio frequency identification, RFID, tags to improve the precision of the positioning. The pseudolite covers the positioning of a few $\mathrm{cm}$ to a couple of decimeter. And the RFID tags cover the local positioning. The floor is equipped with 350 RFID lattice-shaped tags at $300 \mathrm{~mm}$ intervals. Accordingly the robots can freely move around at all.

(3) Moving Module

We have also developed a moving module for the Positioning System. This module can orient itself and program an acting plan. At the same time it has to avoid obstacles. Therefore, we have installed a distance sensor and a supersonic wave sensor into this moving module. Farther, we can easily control it from a computer through the serial connection.

(4) Battery Charge Interface

We are also developing a non-contact battery charge interfaces for robots. So far we came to realize a wall-mounted battery charge station and the device of the robots to supply electricity. The interfaces should monitor the battery voltage at the same instance, inform the beginning and end of charging, and avoid overload. It can be easily connected with a PC through RS-232C connection. Farther more, we have also installed some other equipment in the robot-house. Some of them are shown in Fig.4.4.

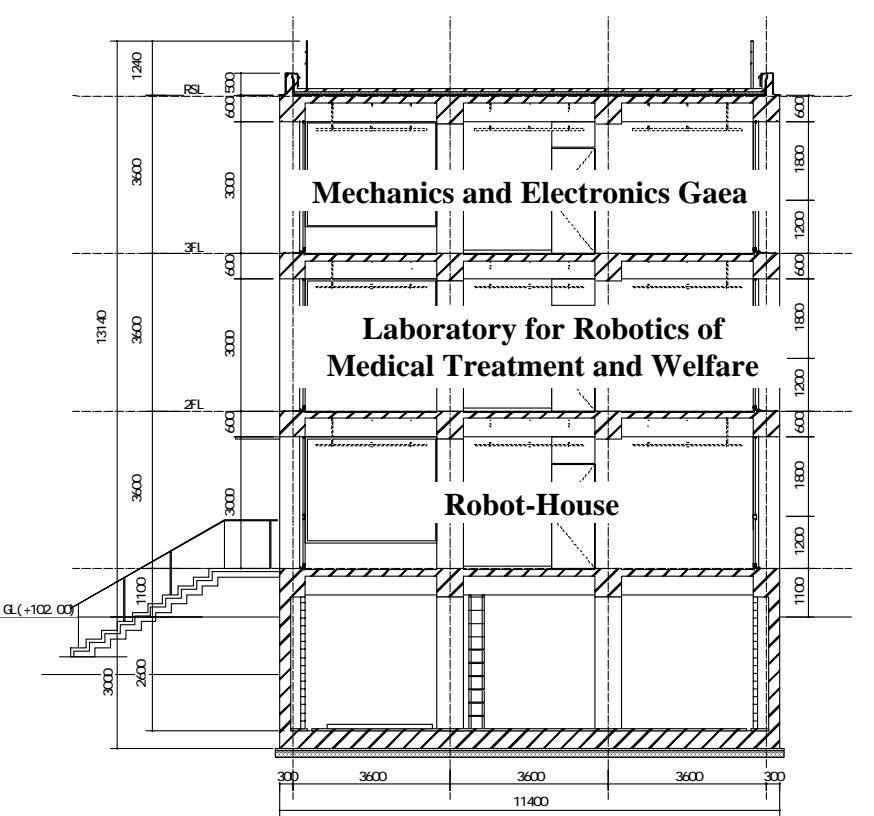

Fig.4.3 A section in the Building B1: Laboratory for Demonstrative Experiments

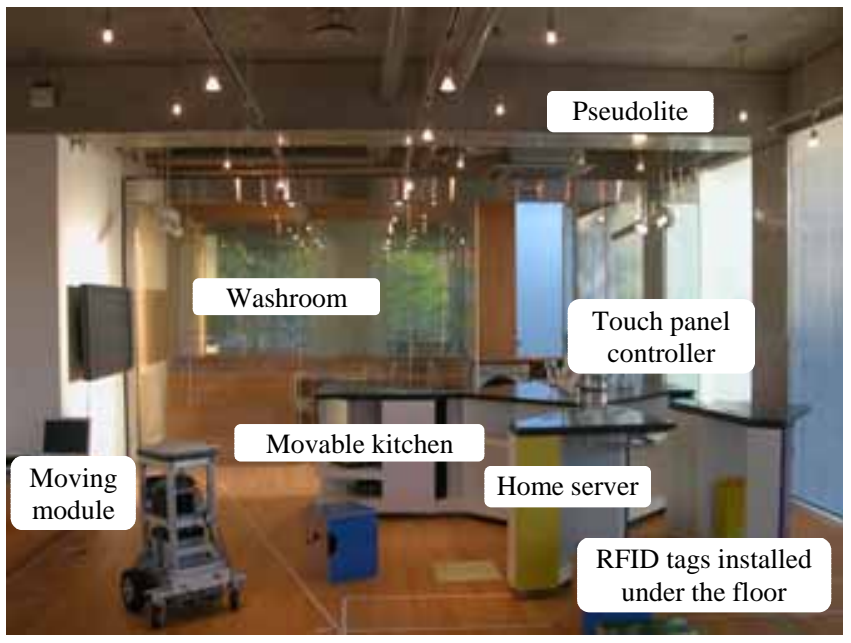

Fig.4.4 Inside "Robot-House”

\subsection{Building C: Space for Robots}

\subsubsection{Design concept}

The building $\mathrm{C}$ is thought as a space for robots. It should be the base for robots in symbiosis with nature, the base for robots' maintenance. It is also a factory where robots produce robots. That is, the building is planned and constructed as a testing site for the robots. It is also an experimental space where experiments can be done safely and freely, even with slightly dangerous robots. The table 4.2 gives the outline of this building.

Table 4.2 Outline of Building C

\begin{tabular}{lc}
\hline Item & Contents \\
\hline Total Floor Area & $432 \mathrm{~m}^{2}$ \\
Building Area & $150 \mathrm{~m}^{2}$ \\
Building Height & $15 \mathrm{~m}$ \\
Planning & Kano Laboratory, Waseda University \\
Design & Kato Institute of structural engineering \\
& \multicolumn{2}{c}{ Sori Equipment Design Office } \\
\hline
\end{tabular}


It is a $12 \mathrm{~m} \times 12 \mathrm{~m} \times 15 \mathrm{~m}$ free indoor space. Inside this building we developed a so called "Floor Adaptable System" consisted of four floor units. Each unit is $6 \mathrm{~m} \times$ $6 \mathrm{~m} \times 0.5 \mathrm{~m}$, which can be modified up and down. With these units the internal space can be resizable requested by robots' activities, experiment and demonstration. Its structure is shown in the figure 4.5. Moreover we are developing "the Environmental Information Delivery System” using a 3D plan, which supports robots' activities in this space, "the Virtual Position System" using a virtual reality technology and "the Personal Identification System" using RFID.

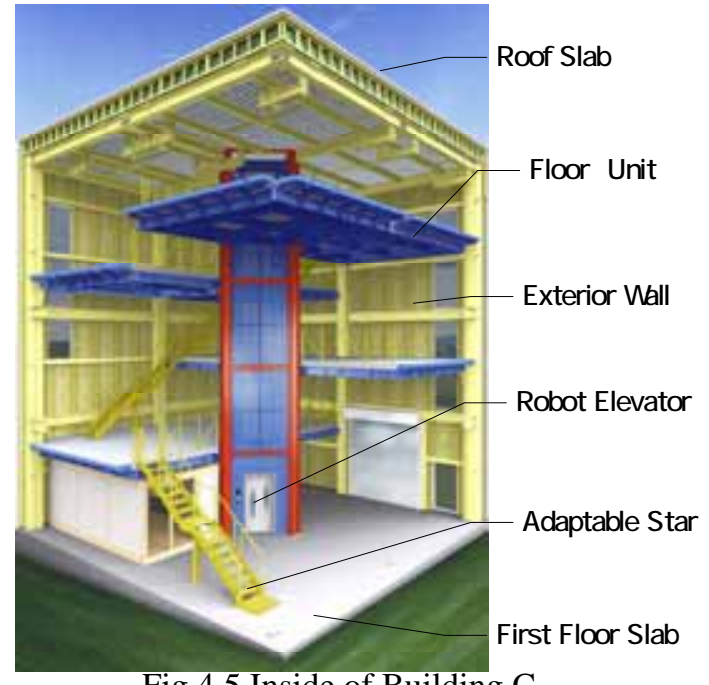

Fig.4.5 Inside of Building C

\subsubsection{Floor Adaptable System}

Inside the building we didn't have settled any wall or floor. Each floor unit can be easily modified up and down. As spoken before, we have developed a system to keep free spacing. This system let different kinds of robots move around without any restriction at all. Each floor unit will be fastened with bolts on the bracket which has the intervals of 200mm bolt-hole. Hydraulic jacks are fixed in every corner of the floor unit, and those pins of the hydraulic jacks put into the guide lots hanged from the ceiling. Then these floors are able to lift up and pull down. We conducted experiment and confirmed that the floor panels can be moved up and down, and the system works precisely. The figure 4.6 shows you the experiment of going up and down of a floor panel.

\subsubsection{Environmental Information Delivery System}

Using a 3D virtual-reality system, we made a database for the component feature which determines the spatial positions in this building. Farther more we have developed a system which provides the users necessary information. Digitizing the construction diagrams by the 3D-CAD, the robots can gather the information about the component feature around themselves in real time. Then they can recognize the space and its position.

\subsubsection{Virtual Positioning System}

In order to show the robots their route, the position coordinate on the components inside the building such as the wall, stairway, doors, is systematized. Moreover a new system was constructed to estimate the position of the robots with graphics gathered by the cameras and the virtual reality system.

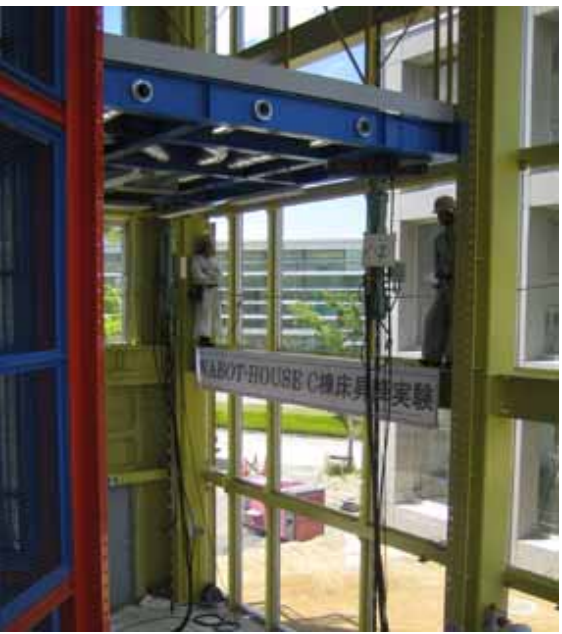

Fig.4.6 Experiment of Going Up and Down of a Floor unit

\subsubsection{Virtual Positioning System}

In order to show the robots their route, the position coordinate on the components inside the building such as the wall, stairway, doors, is systematized. Moreover a new system was constructed to estimate the position of the robots with graphics gathered by the cameras and the virtual reality system.

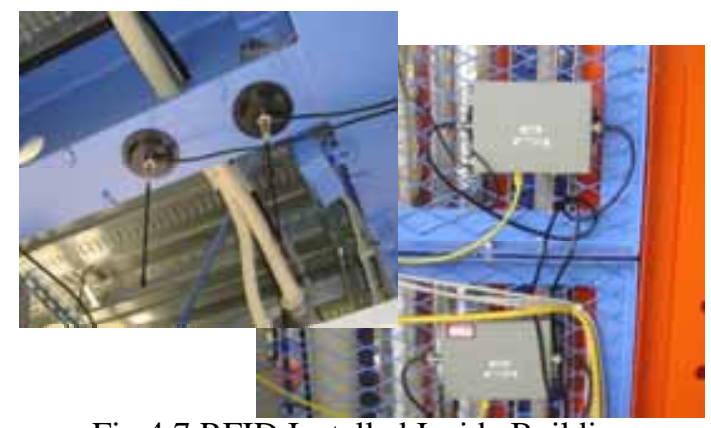

Fig.4.7 RFID Installed Inside Building

\subsubsection{Personal Identification System}

We have developed a new method which gathers and analyzes location information on humans and robots to monitor them using RFID technology. We named it "Personal Identification System". The figure shows the RFID receivers and antennas installed inside this building. Please refer to the following website for the Kano laboratory. URL: http://www.kano.arch.waseda.ac.jp/ 


\section{CO-OPERATION WITH INDUSTRIAL AND ADMINISTRATIVE SECTORS}

Through a survey in Gifu, we found some common needs among different sites.

(1) The sites in need of robots vary from case to case, where you have to consider individual fitted robots from the very beginning. It cannot be just a machine which is mass-produced and consumed for the general use. And the more, it is difficult to increase its productivity by the general-purpose machine.

(2) Robots are expected to work as an extension of human body in the range of functions which require proficient skills and experiences.

(3) The robot industry is a kind of filling-in for the sector, which cannot make profit in the market economy. It is above all useful in community-based industries, such as forestry, household, welfare, security and so on.

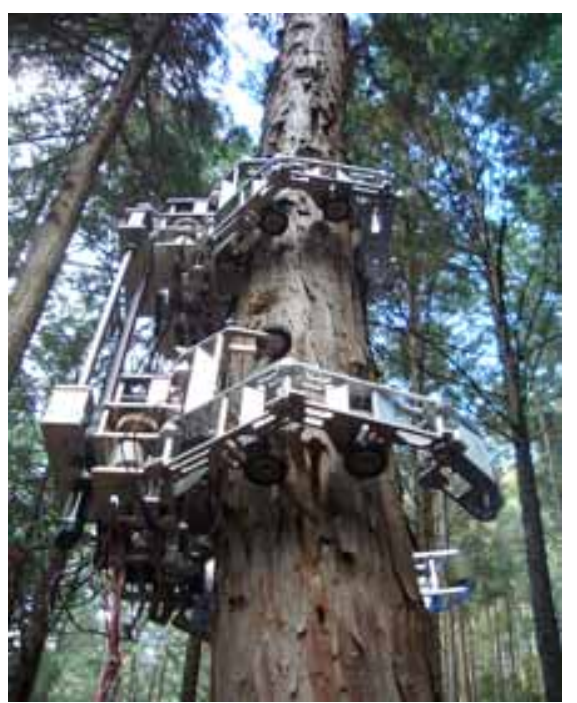

Fig.5.1 WOODY-1 Assisting Forestry Work

Especially the local communities have a serious problem in these fields, because of the different economic standpoint in the globalization nowadays. Although leaning over on technology could be a double-edged sword for the under populated villages, we believe that robotics industry can build a positive vision in local communities. We hope that the robotics industry may reinvigorate local economy to a self-sustaining one.

In order to prepare the lifestyle with robots and to launch the robotic industry from the Gifu prefecture, it is needed to create contrivances for human-robots symbiosis. As a matter of fact, the Kagamigahara-City, where WABOT-HOUSE laboratory locates, has been already designated for the special zone for robotics by the Japanese government. We are ready for conducting the pilot programs for robots. We are expected to consider an innovative space and social system with robotics as a new technology.

As an example we have also paid attention in forestry. In an aging and depopulating local society, we have none who manages the forest resources. Needless to say the forestry industry itself is rapidly declining. The forestry is nowadays worth much more as an environmental issue rather than as market economy. In between a large part of the mountains and their forests has being devastated badly. It causes so many problems all over Japan. Woody-1, the forestry work assist robot, is a sufficient example of collaboration with people in Gifu. We take into consideration not only the mechanization of forest industry but also the conservation of forest. We went out of the laboratory; we have developed that robot under the co-operation with industrial and administrative sectors. Through these activities, WABOT-HOUSE project contributes to promote industrial and regional development in Gifu.

\section{CONCLUSIONS AND FORESIGHT}

As stated above, our WABOT-HOUSE project is dedicated to the environmental design for the human-robot symbiosis. To the next generation, we are trying to generate the multilateral values due to robotics. It needs a close collaboration among industrial, administrative and academic sectors.

Please refer to the following website.

URL: http://www.wabot-house.org/ and

\section{ACKNOWLEDGEMENTS}

This project has not been completed without the cooperation of the Gifu prefecture and a lot of people in the enterprises and the research institutes in Gifu prefecture. Here, it is our pleasure to express our profound appreciation for their good wishes and co-working.

\section{REFERENCES}

[1] N. Kano et al.: "The Book of Wabot No.6", Chuokoron-Shinsya, 2005

[2] S. Sugano et al.: "The Book of Wabot No.5”, Chuokoron-Shinsya, 2004

[3] A. Takanishi et al.: "The Book of Wabot No.4”, Chuokoron-Shinsya, 2004

[4] N. Komatsu et al.: "The Book of Wabot No.3", Chuokoron-Shinsya, 2004

[5] S. Hashimito et al.: "The Book of Wabot No.2”, Chuokoron-Shinsya, 2003

[6] Y. Miwa et al.: "The Book of Wabot No.1”, Chuokoron-Shinsya, 2002

[7] T. Ojima: "Perfect Recycle House II ”, Waseda University Press, 2001. (In Japanese)

[8] T. Ojima: "Perfect Recycle House”, Waseda University Press, 1999. (In Japanese)

[9] Waseda University Humanoid Robotics Institute: "Humanoid Robotics Institute”, 2005.

[10] Y. Shirai: “A Study on the Timber Distribution System and the Balance of the Timber Supply and Demand in the Nagara River Basin Region of the Gifu Prefecture -The Sustainable Development of the Timber Resources due to the Local Industries-”, J. Environ. Eng., Architectural Institute of Japan, Jul.2006. (In Japanese) 